\title{
INTERVENTIONS TO ENHANCE THE TEACHING OF TOXICOLOGY AT A UK UNIVERSITY
}

\author{
A. Peña-Fernández ${ }^{1}$, M.A. Peña ${ }^{2}$, M.C. Lobo-Bedmar ${ }^{3}$, M.D. Evans ${ }^{1}$ \\ ${ }^{1}$ De Montfort University, School of Allied Health Sciences, Faculty of Health and Life \\ Sciences (UNITED KINGDOM) \\ ${ }^{2}$ Universidad de Alcalá, Departamento de Ciencias Biomédicas (SPAIN) \\ ${ }^{3}$ IMIDRA, Departamento de Investigación Agroambiental (SPAIN)
}

\begin{abstract}
Following the recent communication from the European Societies of Toxicology (EUROTOX) advising that toxicology training and expertise is being eroded in the European Union, we have reviewed the teaching status of this subject in all the bioscience undergraduate courses offered at De Montfort University (DMU, UK). The courses reviewed were: Biomedical Science, Health and Wellbeing in Society, Speech and Language Therapy, Medical Science, Pharmaceutical and Cosmetic Science, Forensic Science and Pharmacy. None of these courses dedicate a complete module to the study of toxicology although they teach some aspects of toxicology following the subject-specific threshold standards described by the UK Quality Assurance Agency for Higher Education. Similar results are found in other UK Universities, although a comprehensive study on the status of toxicology teaching is needed. We have not found any undergraduate courses currently offered in the UK that contained the word "toxicology" in their title. These results are in agreement with EUROTOX, which indicated that toxicology has been generally integrated into other bioscience disciplines and is mainly offered as part of a taught postgraduate degree programme in Europe. Owing to these observations, our teaching group is performing different strategies to enhance the teaching of toxicology at DMU as we consider that the learning of this science is critically important to enable future health professionals to protect human health. These strategies included the development of specialised teaching/workshop sessions in toxicology that can be easily included in any undergraduate bioscience module. Thus, during 2016/17 we collected comprehensive feedback (during an Erasmus+ mobility grant for academics) from human health students about their views on the teaching of toxicology and one of the specialised workshops in a programme that does not offer a module in toxicology (BMedSci Medical Science, $\mathrm{DMU}$ ) and one that does (MPharm. Pharmacy, University of San Pablo CEU, Spain). A high proportion of the students consulted requested more teaching of toxicology or the introduction of more specialised toxicology in their programmes. Thus, $85 \%$ of second year BMedSci students indicated that they would like to receive more toxicology training. Also, $42.9 \%(57.1 \%$ neither agree nor disagree) of fourth year MPharm. Students suggested the incorporation of specialised environmental toxicology workshops within their course and all of them considered the environmental toxicology training relevant to their general toxicology module. Other strategies implemented include the enhancement of research in toxicology in our university by offering final projects on these topics to undergraduate and postgraduate students, as well as completion of PhDs. Finally, DMU has recently recruited two toxicologists as academic staff, allowing us to promote the teaching/research of toxicology as well as exploring the possibility of developing postgraduate content for the teaching of toxicology. More efforts should be considered to enhance the teaching of this subject in any bioscience programme, as the current status of toxicology in the UK has been eroded.
\end{abstract}

Keywords: Toxicology teaching, toxicology status, undergraduate and postgraduate students, environmental toxicology.

\section{INTRODUCTION: TOXICOLOGY AS A SCIENTIFIC DISCIPLINE IN THE UK}

Toxicology is a scientific discipline which involves the study of how chemical compounds adversely impact on living organisms. Such chemical compounds include those that occur naturally and those that are produced synthetically, including industrial chemicals, therapeutic and recreational drugs, household cleaning products, cosmetics, herbicides, pesticides, etc. The study of toxicology encompasses basic mechanistic investigations in vitro, through the various levels of organism complexity to toxicological investigations concerned with populations and interactions with the environment. Toxicology is a translational science rooted in basic science and uses theoretical 
knowledge to underpin and inform on practical applications such as risk assessment, protection of public health, response to chemical incidents and bioremediation.

Chemists are thought of as the science professionals most likely to be consulted on toxicological hazards, since most chemical hazard scenarios involve exposure to synthetic chemicals. However, the abundant and frequent use of, and exposure to, synthetic chemicals in multiple environments including those at work, in the home and for therapy mean that healthcare professionals for example are more likely to be concerned with and asked to advise on the potential hazards of these agents. Thus, basic training and knowledge in toxicology would seem an important component of undergraduate training for future healthcare scientists.

Recent communications from the European Societies of Toxicology (EUROTOX) advising that toxicology training and expertise is being eroded in the European Union is echoed in the United Kingdom (UK) [1]. This is evidenced by observations that include the closure of some postgraduate toxicology courses and a reduction in the numbers of academic posts in toxicology, further suggesting that dedicated expertise is being lost or dissipated. Representation of toxicology as a profession does however exist in the UK, this may be through independent or commercial consultancies staffed by former academics or staff from industry with toxicology expertise (e.g. BIBRA, IEH consulting), commercial toxicology testing contractors (e.g. Covance, Safepharm) and in house toxicology testing associated with pharmaceutical companies. Additionally there are government-funded institutes (Public Health England) and those closely affiliated with academic institutes, e.g. Medical Research Council-Public Health England Centre for Environment and Health based at King's College and Imperial College, London. The Medical Toxicology Centre at Newcastle University and Edinburgh Clinical Toxicology bring together academic staff and medically trained staff from the respective universities. Academic institutes are ideally placed to provide academically validated and supported training in toxicology.

However, training in toxicology has limited provision in most human healthcare-related undergraduate degrees and undergraduate degrees in the UK containing the word 'toxicology' are non-existent. This lack of provision of undergraduate degrees with notable toxicology content likely reflects the integration of toxicology into other bioscience disciplines, for example becoming a component of pharmacology teaching or integrated into clinical biochemistry for teaching of medical toxicology. The use of the word 'toxicology' in degree titles is confined to postgraduate qualifications, reflecting the idea that this subject is a topic for specialisation.

Our survey of toxicology teaching in the biosciences/healthcare undergraduate degrees at De Montfort University (DMU; Leicester, UK) shows concordance with general observations in similar UK degree subjects that toxicology teaching has been eroded. While modules focusing exclusively or predominantly on toxicology are absent, some limited coverage of toxicology is evident following the subject-specific threshold standards described by the UK Quality Assurance Agency for Higher Education. However, these general observations have led our teaching group to develop and deliver different strategies to enhance the teaching of toxicology at DMU, since such teaching is critically important for future health professionals to protect human health. Strategies developed by our teaching research team included the development of specialised teaching/workshop sessions in toxicology (specifically environmental toxicology) that can easily be included in any undergraduate bioscience module. Additionally, we are working at DMU towards introducing postgraduate teaching in toxicology. More efforts should be considered to enhance the teaching of toxicology in any bioscience programme, to halt or reverse the current status of apparent toxicology teaching decline in the UK.

\section{INTRODUCTION AND IMPLEMENTATION OF TOXICOLOGY TRAINING IN BIOMEDICAL AND HUMAN HEALTH SCIENCE PROGRAMMES IN THE UK: THE EXAMPLE OF DE MONTFORT UNIVERSITY}

\subsection{Current position of toxicology teaching at DMU}

The situation at DMU provides an ideal opportunity to test and implement strategies for enhancing the awareness and delivery of toxicology teaching generally and in undergraduate biomedical science and healthcare science programmes in particular, notably in the Bachelor's degree programmes BSc. (Hons) Biomedical Science (BMS) and BMedSci (Hons) Medical Science (MedSci) in the School of Allied Health Sciences. As with many other UK institutes offering similar programmes to those at DMU, embedded toxicology teaching is perceived as minimal and at most forms only a minor part of 
some of the modules offered in the above programmes. In the BMS programme, toxicology is covered briefly in the context of medical toxicology to include very brief coverage of background toxicology concepts as a single lecture in the level 6 module on 'Clinical Biochemistry' attended by both BMS and MedSci students. In the level 6 MedSci module 'Pharmacology \& Therapeutics' there is a little more extensive coverage of toxicology-related subjects with 4 individual lectures covering absorption, distribution, metabolism and excretion. Both of these modules are delivered in the final year as part of more specialist and focused modules re-enforcing impressions that toxicology is a specialist subject. At levels 4 and 5, briefer mention of toxicology-related material in selected lectures is made by some academic staff drawing on their research interests or prior experience of delivering on toxicology. These briefer references in selected lectures are presented in the context of 'real-world' examples of toxicology, attesting to and illustrating the applied nature of the subject, such examples include dioxin exposure as a result of the Seveso, Italy industrial accident in 1976, methylmercury poisoning in Minimata, the attempted poisoning of Victor Yuschenko with dioxin and the monitoring of environmental contamination by metals and metalloids. Although introduction of the word 'toxicology' as a subject area is not specifically mentioned, it would be prudent to use this term in future.

\subsection{Strategies for implementation of toxicology teaching}

The use of short, dynamic and interactive toxicology-focused workshops could be an effective method to embed toxicology teaching in existing modules and enhancing the current academic status of toxicology; e.g. by delivering toxicology concepts to undergraduates in biomedical and health sciences as well as illustrating the importance of the subject in protecting human and environmental health as well as raising awareness of toxicology as a scientific discipline. Such examples of toxicology concepts in the context of 'real life' scenarios also show students the value of toxicology as a subject, its applied nature and relevance, compared to some subject areas (e.g. physical chemistry) which could be perceived as more esoteric and where it may be difficult to envision practical applications.

This approach of using specialised workshops to deliver training in toxicology, using environmental toxicology as the focus, was trialed in the MedSci programme at DMU using prior experience of high student satisfaction from similar workshops delivered to year 4 students enrolled in the toxicology module of the bilingual pharmacy Bachelor's degree in Pharmacy at the University of San Pablo CEU (USP-CEU, Spain) [2]. The nature of these workshops has been described by Peña-Fernández et al. [2-4]. These toxicology workshops modelled on those delivered at USP-CEU were adapted for use at DMU in the BMS and MedSci programmes. The students' opinions on the workshop were gathered via a post-session questionnaire using a Likert scale for answer options and free text boxes for comments. Similar to the experience of the students at USP-CEU a high level of satisfaction was noted for the DMU students along with support for the introduction of more toxicology-focused training in the programmes $[4,5]$.

Strategies for enhancing the visibility of toxicology and its teaching at DMU are depicted in Figure 1 and include the wider use of workshops such as those implemented and tested in this report and expanding the workshops to relevant degree programmes within the School. The development of research activity in toxicology will underpin the delivery of teaching in toxicology, for example staff are more likely to use examples from toxicology to illustrate taught concepts. Toxicology research activity is being developed by the use of final year honours projects with a toxicology focus and the creation of $\mathrm{PhD}$ or other postgraduate research positions with a significant component of toxicology. The recent recruitment of two members of academic staff with a toxicology background is enhancing the development and provision of toxicology teaching at DMU. Finally, taught postgraduate provision of toxicology teaching at DMU is being enabled by the presence of these staff, along with development of a toxicology-based MSc. programme. This programme is proposed to cover the full remit of toxicology concepts from molecular toxicology through to environmental toxicology and legal perspectives, incorporating a 60 credit project module. The creation of a toxicology research group bringing together academic staff and postgraduates working in this area would consolidate toxicology provision at DMU. 


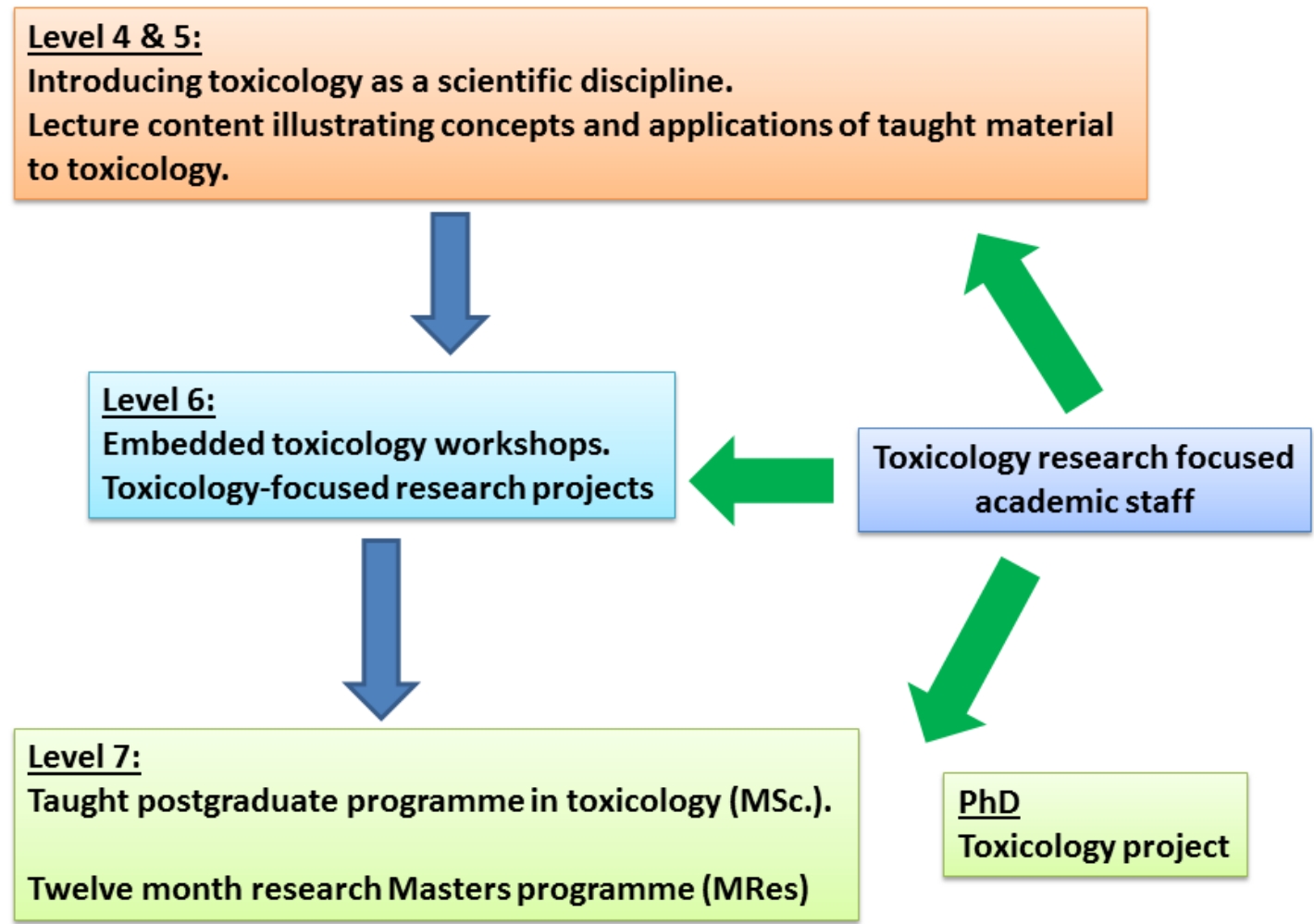

Figure 1. Strategies to enhance visibility and training in toxicology at De Montfort University, Leicester, UK.

\section{CONCLUSIONS}

The above strategies, some of which are in development, are laying the foundation for awareness of the practice and importance of toxicology as a scientific discipline across the biomedical and healthcare science undergraduate programmes at DMU (summarised in this paper). These strategies are starting early in the academic careers of the undergraduate students (levels 4 and 5) by introduction of toxicology as a scientific discipline and illustrations of this discipline and its applications. Toxicology is re-enforced in the final year, level 6, by the introduction of longer, toxicology-focused interactive workshops embedded into pre-existing modules and the provision of toxicology honours research projects by appropriate staff. The presence of toxicology as an active research subject and scientific discipline at DMU, including badging of staff research areas as 'toxicology', would be strengthened by the provision of an active toxicology research community through the development of a toxicology-focused MSc. and post-graduate research projects (MRes, PhD) in toxicology. In addition to the implementation of these in the biomedical and healthcare sciences programmes at DMU, a comprehensive and accurate review of the current situation as regards toxicology training at undergraduate level in the UK is warranted.

\section{REFERENCES}

[1] H. Wallace, R. Roberts, E. Corsini, E. Bonefeld-Jorgensen et al. Toxicology as an academic discipline in European universities. Toxicol. Lett., 2016; 254:3.

[2] A. Peña-Fernández, M.D. Evans, A. Magnet, F. Izquierdo, C. del Águila. Introducing training to respond to chemical incidents in the pharmacy degree at the University of San Pablo CEU (Spain). EDULEARN 2017 Proceedings; 5086-5091.

[3] A. Peña-Fernández, M.J. González-Muñoz, M.A. Peña. Designing training for teaching environmental toxicology to specialized pharmacists. Currents in Pharmacy Teaching and Learning 2015; 7: 864-868. 
[4] A. Peña-Fernández, M.A. Peña, M.C. Lobo-Bedmar, M.D. Evans. New challenges for environmental toxicology education in the European Union. ICERI 2016 Proceedings; 43574364

[5] B. Escalera Izquierdo, M.A. Peña, M.D. Evans, A. Peña-Fernández. Implementation of chemical incident training in human health programmes. In: Research in university teaching. Designing the future based on educational innovation (Ed. R. Roig-Vila). Barcelona: Octaedro, 2017; pp. 193-202. 